\title{
Dynamic Performance of Particles Loaded Cross-Plied GFRP Composite
}

\author{
Aayush Bansal, Aje ya Gupta, Mohit Pundir, Vibhas Mishra, V.K. Srivastava* \\ Department of Mechanical Engineering, Indian Institute of Technology, BHU, Varanasi, 221005, India
}

\begin{abstract}
Fiber reinforced polymer composites (FRPs) are being increasingly used for a wide range of engineering applications owing to their high specific strength and stiffness. However, there through-the-thickness performance lacks some of the most demanding physical and mechanical property requirements for structural applications, such as aerospace vehicles and military components. Charpy impact test was done on end notched specimens of cross-plied glass fiber reinforced epoxy resin (GFRP) composites. Alumina and flyash particles were added in the epoxy resin with the weight ratio of $2.5 \%$. The effect of notched length and fillers on dynamic performance of GFRP composite was obtained. Finally, SEM images were used to exp lain the changes in mechanical properties.
\end{abstract}

Keywo rds Glass Fiber, Epo xy Resin, A lu mina, Flyash, Charpy Impact Energy, Dynamic Fracture Toughness, Scanning Electron Microscope

\section{Introduction}

Fiber re inforced po ly mer co mposites poss ess high specific moduli and specific strengths and are widely used in many structural applications including aerospace, sporting goods, automobile, civil and marine structures. While the inplane and fiber dominant properties make these composites useful in these applications, their through-the-thickness properties are limited by the relatively poor properties of the matrix resin and the weak fiber-matrix interfacial bond. In order for FRPs to offer better choice for aerospace and military components over monolithic metallic structures possessing no delamination problems, significant improvements in the through-the-thickness properties are necessary.

It is well known that composite structures in the form of laminates are extremely susceptible to crack initiation and propagation along the laminar interfaces in various failure modes. In fact, delamination is one of the most prevalent life-limiting crack growth modes in laminate composites as delamination may cause severe reductions in in-plane strength and stiffness, leading to catastrophic failure of the whole structure[1]. Delamination may be introduced by external loading as in static bending, compression or tension, in cyclic fatigue or by impacts of low-to-high energies, during manufacturing or in service.

Impact loading during service is a common phenomenon

* Corresponding author:

vijayks210@gmail.com (V.K. Srivastava)

Published online at http://journal.sapub.org/cmaterials

Copyright (C) 2012 Scientific \& Academic Publishing. All Rights Reserved for aerospace composite structures. There are situations like tool drops, runway debris, bird strikes, hailstorms and ballistic strikes, which induce considerable damage to the composite. In order to produce an impact resistant structure, it is important to understand the dynamics of the impact event and thus to predict the extent of the induced damage and estimate the residual properties so that the composites are designed with improved structural integrity and mechanical performance after impact[2-3]. Many useful techniques have been successfully devised to improve the delamination resistance in the past three decades[4-7]. In addition to the resistance to interlaminar fracture and impact damage, FRPs for advanced aerospace structures often require the most demanding multi-functional properties. The introduction of nanotechnology in the field of composite materials with nanoscale fillers, such as carbon nanotubes (CNTs) and carbon nanofibers (CNFs), has offered new opportunities to improve these mechan ical and multifunctio nal properties of FRPs [8]. In light of their excellent Young's modulus and strength, extremely high aspect ratio, large surface area, and excellent thermal and electrical properties, these nanofillers can be incorporated into the FRPs to modify the properties of polymer matrix[9-11].

This paper aims to provide an overview of the enhancement of charpy impact energy and dynamic charpy impact toughness properties of GFRPs, especially the impact and delamination resistance, arising from the incorporation of alu mina and flyash fillers in the composites.

\section{Experimentation}




\subsection{Materials and Sample Preparation}

The composites were made from commercially available 90/0 Cross-ply E-Glass Fibre. The matrix material was Epoxy resin, which is procured from Resinova Chemie Ltd., Kanpur, India. The epoxy resin was contained Araldite (LY-554) and hardener (HY-951). They were mixed properly with the weight ratio 10:1.

The fly-ash was obtained from Obra Thermal Power Station, Mirzapur, U.P. India. The fly ash powder is a mixture of different chemical constituents such as Silica (56.04\%), A lumina (24.90\%), $\mathrm{FeO} / \mathrm{Fe}_{2} \mathrm{O}_{3}(1.26 \%), \mathrm{CaO}$ (2.2\%), $\mathrm{MgO}(0.94 \%)$ and unburned coal etc. The physical properties of fly-ash include density $(3.385 \mathrm{~g} / \mathrm{cc})$, porosity (0.38) and particle diameter $(63-105 \mu \mathrm{m})$.

The alu mina powder was of Sasol, Germany. The particle size was in the range of $15-60 \mu \mathrm{m}$. The mixture has an alu mina percentage of $72-77 \%$. The surface area is $170-250$ $\mathrm{m}^{2} / \mathrm{g}$. The crystalline size of a lu mina powder is $4.5-10 \mathrm{~nm}$.

Hand lay-up method was used for the fabrication of composite specimens. Fourteen layers of cross-plied E-glass-fiber sheets were composed with the epoxy resin to make a single large composite plate. The resin and hardener were taken in the ratio of 10:1 by weight. A constant load of $20 \mathrm{~kg}$ was placed on the top of layer to control the weight ratio of fiber and epoxy resin, because excess amount of epoxy resin was squeezed out from the inside the fiber layers. The specimen was left for curing at a mb ient conditions under the influence off applied weights for 24 hours. Later on post curing was done in furnace at $50-60^{\circ} \mathrm{C}$ for $1 \mathrm{hr}$. Similarly, specimen 2 and 3 was fabricated with the introduction fillers in epoxy resin before the addition of hardener.

Three different composites were made. In itially, plain GFRP without filler material was prepared. Later, it was blended with $2.5 \%$ Fly-ash by weight of epoxy and with $2.5 \%$ A lumina by weight of epoxy respectively (which is referred as specimen 1, 2 and 3 respectively).

The weight fraction of the glass in the composite was controlled through the application of weights during curing. However, burn-off method was used to measure the exact weight ratio of fiber and epoxy resin. First, composite specimen $(10 \times 10 \mathrm{~mm})$ was weighted and placed in crucible. The crucible with composite template was kept in furnace at $250^{\circ} \mathrm{C}$ for $5 \mathrm{hr}$. The epoxy resin was burn out and then the weight of fiber was measured. Finally, weight fraction of glass fiber and epoxy resin was obtained as 0.541 in specimen-1, 0.5327 in specimen-2 and 0.4663 in specimen-3 respectively.

The composite plates obtained above were then cut into ENF specimen, which dimension is shown in Figure 1.

For each specimen (i.e. 1, 2, and 3) three different notch lengths were made as shown in the Table 1 . The in itial notch length was introduced by placing thick plastic sheet between glass ply 7 and 8 during the Hand-Layup procedure. The notch was later opened through a sharp knife-edge and mallet.

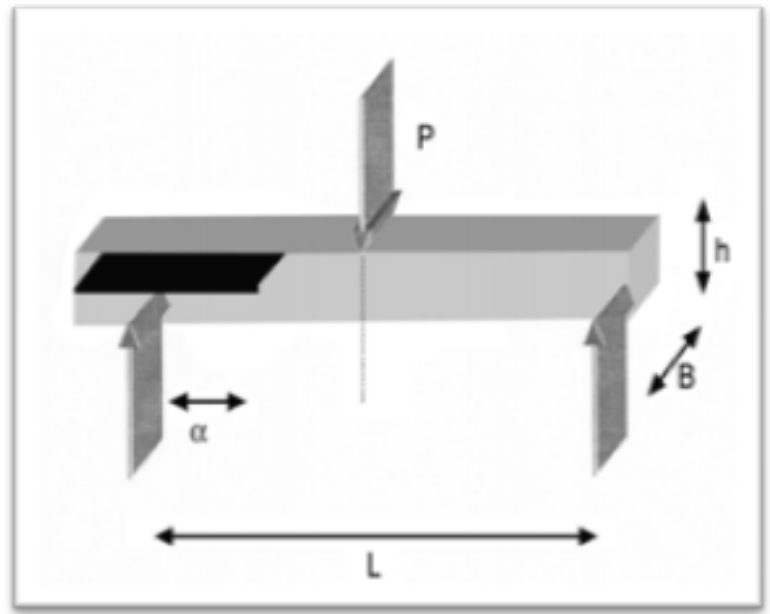

Figure 1. Schematic diagram of End-notched specimen

Table 1. Specimen Dimensions

\begin{tabular}{ccccc}
\hline $\begin{array}{c}\text { Specimen } \\
\text { No. }\end{array}$ & $\begin{array}{c}\text { Length } \\
\text { L (mm) }\end{array}$ & $\begin{array}{c}\text { Breadth } \\
\text { B (mm) }\end{array}$ & $\begin{array}{c}\text { Height } \\
\mathbf{h}(\mathbf{m m})\end{array}$ & $\begin{array}{c}\text { Initial Crack } \\
\text { Length } \boldsymbol{\alpha}(\mathbf{m m})\end{array}$ \\
\hline $\mathbf{1}$ & 124 & 10.20 & 6 & $17.7,25.4,43.1$ \\
$\mathbf{2}$ & 124 & 10.40 & 6.5 & $25.4,43.1,50.8$ \\
$\mathbf{3}$ & 124 & 10.30 & 7.2 & $25.4,43.1,50.8$ \\
\hline
\end{tabular}

\subsection{Charpy Impact Test}

The impact test was performed with instrumented charpy equipment (Model; Resil Impactor-50, CEAST, S.p.A., Italy), as shown in Fig. 2. The impact-hammer and vice lever with specimen adapter used were according to Charpy impact test. The impact length and impact velocity were $0.327 \mathrm{~m}$ and $3.46 \mathrm{~m} / \mathrm{s}$.

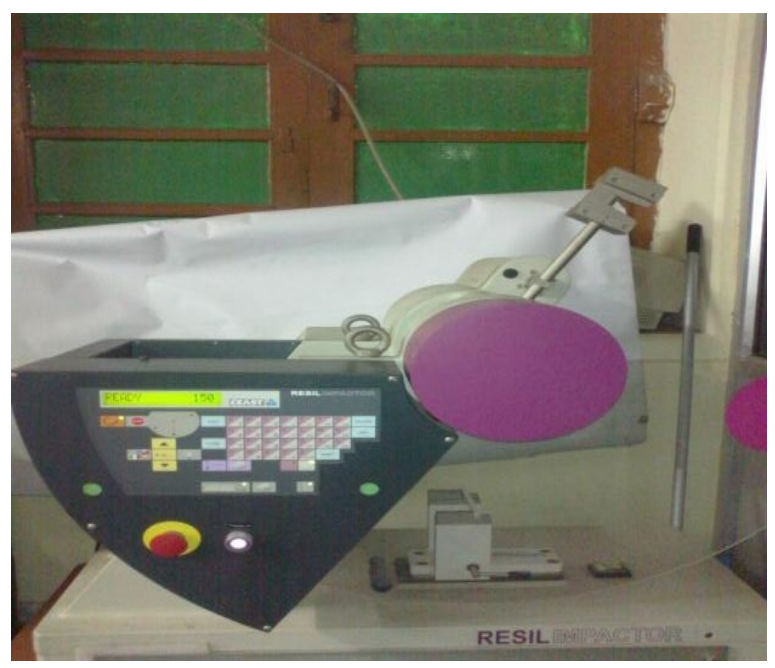

Figure 2. Photograph of Resil charpy impact test

Charpy test was performed on ten ENF samples of each class of composites (type-1, 2, and 3). The average results were reported to obtain the impact energy and toughness of each sample. The impact energy required for each specimen was indicated by the machine and was recorded. The fractured specimens are presented in Fig. 3. 


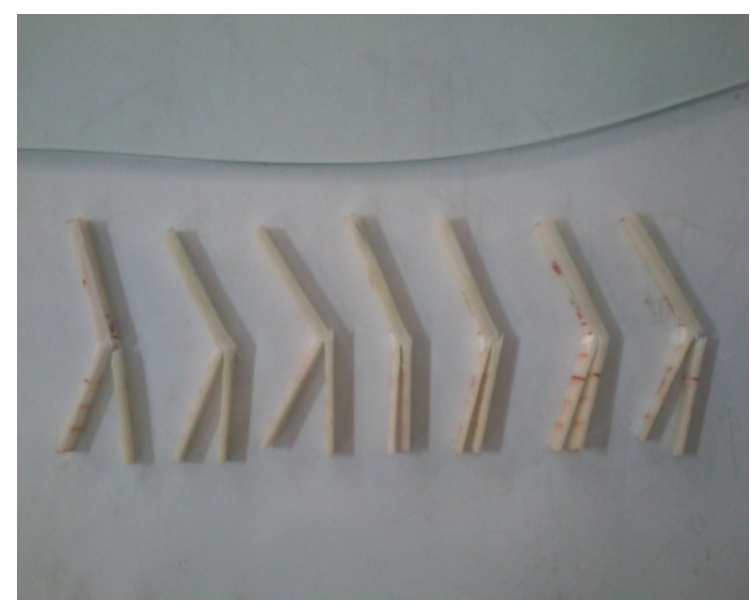

Figure 3. Fractured specimens under impact test

\subsection{Scanning Electron Microscopy Test}

The fractography study was used with the help of scanning electron microscopy (SEM), Philips-XL-20, which is available in the Dept. of Physics, BHU. For SEMobservatio $\mathrm{n}$ on the fractured specimens, the black soot-like material was directly mounted to the sample holder with silver glue which is electrically conductive.

\section{Results and Discussion}

\subsection{Variation of Impact Energy}

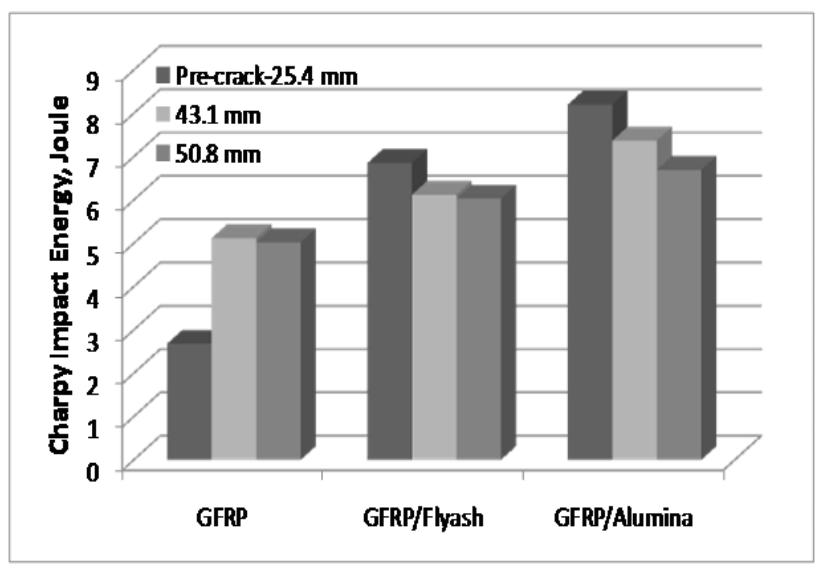

Figure 4. Variation of charpy impact energy with specimen

Fig. 4 shows the variation of impact energy with change in the initial crack length of different specimen made by third phase in the addition of to cross-plied E-glass fiber reinforc ed epoxy resin composites. The results clearly indicate that the variation in impact energy with the initial crack lengths 25.4, 43.1 and $50.8 \mathrm{~mm}$ respectively. Since, the specimen goes under delamination under the dynamic impact loading condition (Charpy impact test) therefore the specimen with lowest initial crack length would absorbed more energy for delamination, which is explained by the graph (as dela mination occurred till the point of impact), i.e. specimen with lowest initial crack length $25.4 \mathrm{~mm}$ has absorbed more energy than any other sample in both cases, while, the specimen with higher in itial crack length has absorbed lower energy than other samples [4].

For the specimen-1 the crack didn't propagated for 25.4 $\mathrm{mm}$ and $17.4 \mathrm{~mm}$ initial crack length. This shows that the min imu m initial crack length of 25.4, $43.1 \mathrm{~mm}$ specimen is required. However, for specimen-2 and 3 the crack propagated for $25.4 \mathrm{~mm}$ initial crack length. This shows an increase in delamination tendency of GFRP with fillers but with increase in absorbed impact energy. The results of sample of same composition and same in itial crack length showed that impact energy increases with change in crack length for every case. Hence, it can be concluded from the results that the impact energy absorbed by the specimen goes mostly in increasing the crack length[6]. Hence, energy main ly goes in delamination.

\subsection{Variation of Dynamic Fracture Toughness}

The dynamic fracture toughness can be obtained fro $m$ the following relation, which is given below

$$
\mathrm{K}_{\mathrm{dc}}=\mathrm{I} /(\mathrm{h} \mathrm{x} \mathrm{w})
$$

where, I, $\mathrm{h}$ and $\mathrm{w}$ are Impact Energy, breadth and width of the specimen.

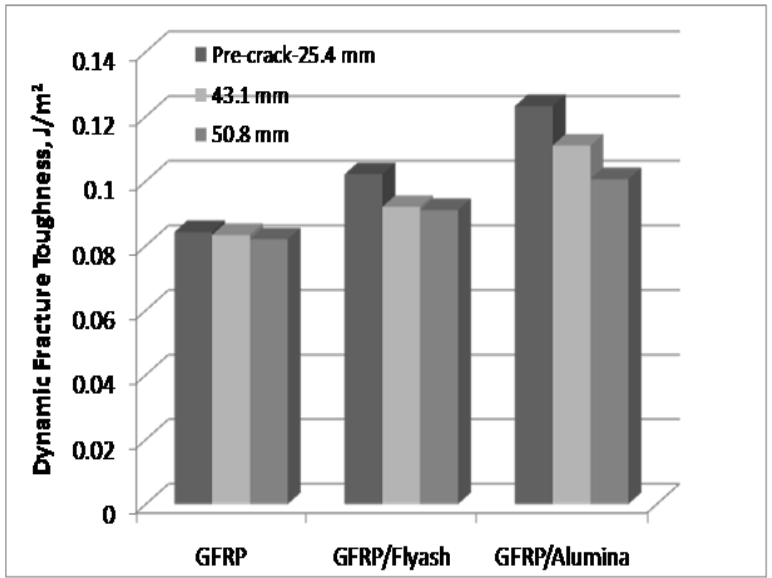

Figure 5. Variation of dynamic fracturetoughness with the specimens

Fig. 5 shows the value of average dynamic fracture toughness for different specimen of different composition, such as flyash/GFRP, a lu mina/GFRP and GFRP composites with the variation in initial crack length ranging from $25.4,43.1,50.8 \mathrm{~mm}$, respectively. It can be observed from the graph that dynamic fractures toughness of GFRP composite is lower than the flyash/GFRP and alumina /GFRP samples. Thus, samples of alumina have higher dynamic fracture toughness value, which has been explained with the help of SEM images of the samples.

In all cases the value of average dynamic fracture toug hness of alumina samples are more than the flyash/GFRP and GFRP samples. This indicates that alumina particles increase the interface bond strength between epoxy resins, which increase the toughness of GFRP co mposites[7].

\subsection{Microscopy Analysis}


SEM images for GFRP sample shows matrix failure and de-bonding as visible in Figure 6. There is no fibre breakage in the de-lamination area. The fibres are shown in micrograph by region $\mathrm{A}$. The matrix left after de-bonding is shown by region $\mathrm{B}$.

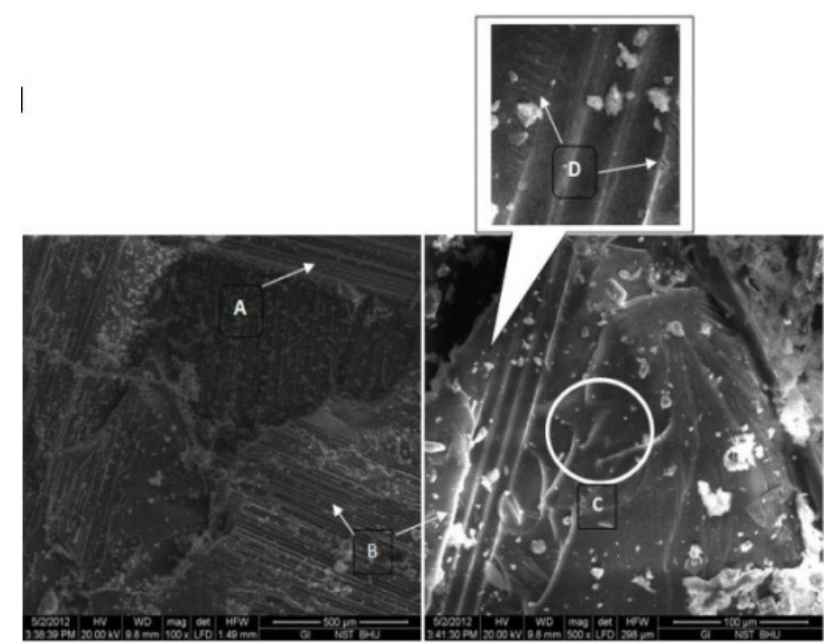

Figure 6. SEM images for fractured specimen of GFRP composite

There is considerable brittle failure of matrix as shown by region C. In Figure 7, minute crack flow lines are seen around the de-bonded region D because the energy is trans mitted through the matrix to the fibre resulting in de-bonding. De-bonding shows weak fibre-matrix interface $[7,8]$.

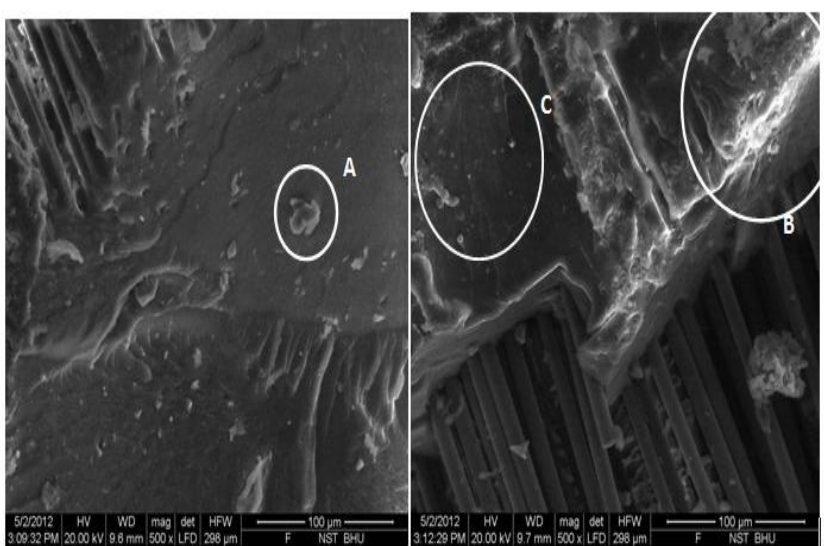

Figure 7. SEM images for fractured specimen of flyash/GFRP composite

SEM analysis of the Fly-ash specimen shows distribution of fly ash particles in the matrix, resin fly ash interface, glass fibre distribution in the matrix, glass fibre matrix interface, deformation behaviour etc[9]. This appeared that the maximum cracks are visible in the flayash/epoxy resin rich area, as shown in Fig. 8.

It was observed that the fly-ash particles basically contain the metal oxide, as the particles are not spherical (Fig. 7-A). Also the mixing is rather heterogeneous, containing the lumps of the fly-ash (Fig. 7-A). The fly-ash sites where the large clusters were there acted as the site of stress-concentra tion, resulting in the initiation of cracks (Fig. 7 - B) On the other hand, where the particles are well distributed and are small, and the area resisted the dislocation's movement.

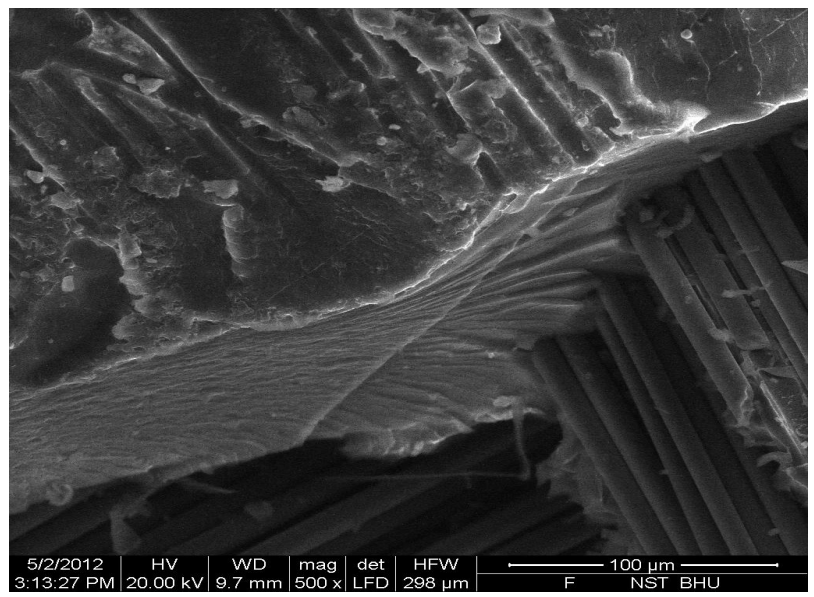

Figure 8. Flyash mixed resin fractured in different plane

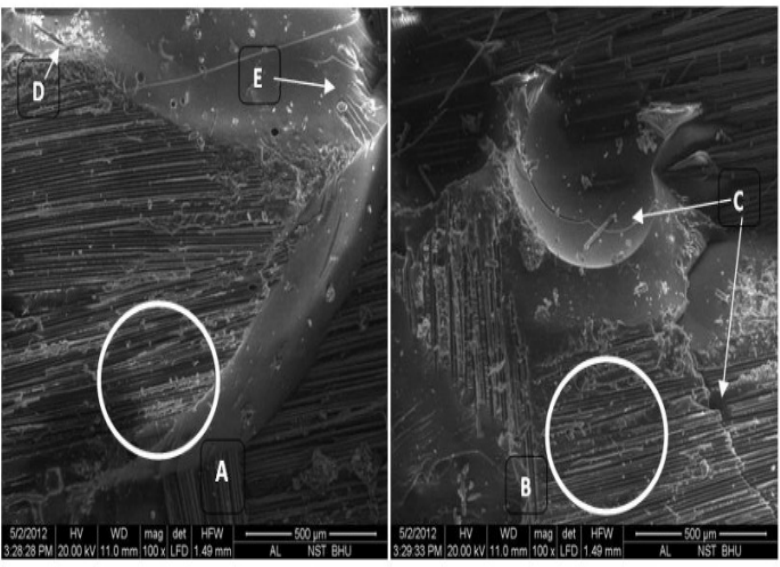

Figure 9. SEM images for fractured specimen of alumina/GFRP composite

SEM images for alumina/GFRP composite sample indic ate that there is no fibre failure in the de-lamination area[10]. There is significant de-bonding between fibre and matrix as shown by region $\mathrm{A}$ and $\mathrm{B}$. The matrix underwent brittle failure as shown by $\mathrm{C}$ in Figure 9. The fracture toughness of sample improved considerably because the alu mina particles converted into nano particles leading to large increase in surface area. This increase in surface area results in absorption of large amount of impact energy[11]. However, as visible from the SEM there was improper mixing of alumina leading to clusters. These clusters acted as stressconcentrati on point shown by D. As cluster size decreases crack flow lines are vis ible as shown by E. Small voids are also visible.

\section{Conclusions}

The experimental results confirmed that the addition of filler improved the toughness of GFRP composite under dynamic loading. In the case of a lu mina, dynamic fracture toughness, $\mathrm{K}_{\mathrm{dC}}$, was more than the flyash filled GFRP composites, because, the shape and size of fillers play a key role in changing the toughness of the matrix. Also, 
micrographs showed that cracks were arrested by the particles and most of the fibres fractured due to increase of interface bond strength.

\section{ACKNOWLEGEMENTS}

The authors would like to thank Prof. O.N. Srivastava, Department of Physics, BHU, Varanasi for providing the SEM facilities. Also, authors are thankful to Mr. Kali Prasa d, Mechanic, Mr. R. P. Singh, Lab Attended, Experimental Mechanics Laboratory, Department of MechanicalEngineer ing, Indian Institute of Technology, BHU, Varanasi, India for their supports during the experimental work.

\section{REFERENCES}

[1] Y Hirai, H Hamada, JK Kim, Impact response of woven glass-fabric composites-I Effect of fiber surface treatment, Composites Science and Technology, 58, 91-104, 1998.

[2] Y Hirai, H Hamada, JK Kim, Impact response of woven glass-fabric composites-II Effect of temperature, Composites Science and Technology, 58, 119-128, 1998.

[3] JK Kim, YW Mai, Engineered interfaces in fiber reinforced composites, $1^{\text {st }}$ ed. New York, Elsevier Sciences, 1998.
[4] JK Kim, ML Sham, Impact and delamination failure of woven fabric composites, Composites Science and Technology, 60, 745-761, 2001

[5] J Li, JK Kim, Percolation threshold of conducting polymer composites containing 3D randomly distributed graphite nanoplatelets, Composites Science and Technology, 67, 2114-2120, 2007.

[6] FS Liao, AC Su, TCJ Hsu, Vibration damping of interleaved carbon fiber-epoxy composite beams, J. of Composite Materials, 28, 1840-1854, 1994.

[7] JK Kim, C Baillie, YW Mai, Fracture toughness of CFRP with modified epoxy resin matrices, Composites Science and Technology, 43, 263-297, 1992.

[8] SU Khan, JK Kim, Impact and delamination failure of multiscale carbon nanotubes-fiber reinforced polymer composites- A review, Int. J. of Aeronautical and Space Sci. 12 (2), 115-133, 2011.

[9] M Hojo, S Matsuda, M Tanaka, S. Ochiai, A Murakami, Mode I delamination fatigue properties of interlayer-toughen ed CF/epoxy laminates, Composites Science and Technology, 66, 665-675, 2006.

[10] K Iqbal, SU Khan, A Munir, JK Kim, Impact damage resistance of CFRP and nanoclay-filled epoxy matrix, Composites Science and Technology, 69, 1949-1957, 2009.

[11] D Alhazov, E Zussman, Study of the energy absorption of laminated glass using carbon nanotubes, Composites Science and Technology, 72, 681-687, 2012. 